\title{
Relationship Between Physical Disability, Disease Activity and Osteoporosis in Patients With Rheumatoid Arthritis
}

\author{
Mihailov Claudia ILEANA, ${ }^{1}$ Mitroi Adrian NELUTU ${ }^{2}$ \\ ${ }^{1}$ Department of Medical Semiology, Faculty of Medicine, Ovidius University of Constanta, \\ Clinical Port Hospital of Constanta, $2^{\text {nd }}$ Medical Department, Constanta, Romania \\ ${ }^{2}$ Clinical Railway Hospital Constanta, The $2^{\text {nd }}$ Medical Department, Constanta, Romania
}

\begin{abstract}
Objectives: This study aims to assess the relationship between the physical disability, degree of disease activity, and bone mineral density in menopause patients diagnosed with rheumatoid arthritis (RA).

Patients and methods: The study included 130 females (mean age $62.77 \pm 7.51$ years; range 57 to 69 years) who reached menopause, and were diagnosed with RA. Bone mineral density was measured at the lumbar spine level and femur (femur head, entire femur) through osteodensitometry with dual X-ray absorptiometry. Age, weight, height, body mass index, environment (urban, rural), age of the menarche and the onset of menopause, duration of menopause, smoker/non-smoker status, RA stage, RA onset age, duration of RA, extra-articular manifestations, the presence of rheumatoid factor, erythrocyte sedimentation rate, $C$ reactive protein, disease activity score 28 , and physical disability quantified by modified health assessment questionnaire were used for evaluating the RA activity.

Results: The mean body mass index was $27.74 \pm 4.37 \mathrm{~kg} / \mathrm{m}^{2}$, the mean duration of menopause was $16.42 \pm 8.15$ years. About $44.62 \%$ of the patients had osteoporosis. Osteoporosis frequency increased with RA stage: $23.81 \%$ in stage II, $55.0 \%$ in stage III, and $77.78 \%$ in stage IV. About $58 \%$ of the patients received prednisone treatment. Independent risk factors for osteoporosis were: age, environment, body mass index, duration of menopause, rheumatoid factor presence and extra-articular manifestations, duration of RA, modified health assessment questionnaire, erythrocyte sedimentation rate and $\mathrm{C}$ reactive protein.
\end{abstract}

Conclusion: Physical disability and disease activity contribute to the occurrence of osteoporosis in patients diagnosed with RA.

Key words: Disease activity score; menopause; osteoporosis; rheumatoid arthritis.

Rheumatoid arthritis (RA) is a disease characterized by a systemic chronic inflammation which mainly affects the joints through cytokines, chemokines and metalloproteinases. Osteoporosis (OP) is considered to be an extra-articular manifestation of $\mathrm{RA},{ }^{1}$ with the prevalence of OP being higher in RA patients than in the general population. ${ }^{2}$

Potential etiological factors include glucocorticoid treatment, decreased physical activity with progressive disease, and a direct effect of inflammatory mediators on bone turn- over. Current controversies include how these factors could influence the RA patients. The influence of these factors is likely to be more clearly defined nearly in the disease process, when bone mass is highest and change is more easily quantified since there is less influence of previous treatment or the manifestation of the menopause period. ${ }^{3}$

This study aims to assess the relationship between physical disability, disease activity, and bone mineral density (BMD) in postmenopausal patients with RA. 


\section{PATIENTS AND METHODS}

The study included 130 women (mean age $62.77 \pm 7.51$ years; range 57 to 69 years) followed by the Rheumatology Clinic in the Clinical Emergency Hospital of Constanta and Clinical Railway Hospital Constanta between January 2008 and January 2010. The women reached menopause at ages between 49 and 75 years. Inclusion criteria were as follows: postmenopausal women meeting American College of Rheumatology 1987 revised criteria for RA, with disease duration of more than two years. ${ }^{4}$ Exclusion criteria were as follows: having secondary OP related with an etiology other than RA, and taking corticosteroid treatment for diseases such as hyperparathyroidism, thyroid disease, and diabetes mellitus, having no BMD measurement.

Demographic variables related to RA and therapeutic variables of the patients were obtained through patient interviews. The following variables were collected: age, weight, height, body mass index (BMI), environment (urban, rural), age at menarche and the onset of menopause, duration of menopause, smoker/non-smoker status, BMD, RA stage, age at onset of RA, duration of RA, extra-articular manifestations (represented by simple chronic anemia, pulmonary fibrosis and rheumatoid nodules), the presence of rheumatoid factor (RF), erythrocyte sedimentation rate (ESR), C-reactive protein (CRP), disease activity score 28 (DAS28), and physical disability quantified by modified health assessment questionnaire (mHAQ). Treatment included disease modifying antirheumatic drugs and corticosteroids.

Global assessment of disease activity was performed by measurement on a visual analog scale from 0 to $100 \mathrm{~mm}$. Disease activity score 28 was calculated by assessing the 28 tender joint count and 28 swollen joint count, ${ }^{5}$ and ESR was calculated by the Westergren method. ${ }^{6}$ Physical disability was assessed by the mHAQ. ${ }^{7}$ C-reactive protein was estimated by the NycoCard Reader. ${ }^{8}$ Bone mineral density was measured at the lumbar spine $\left(\mathrm{L}_{2}-\mathrm{L}_{4}\right)$ and femur and femoral neck by dual energy X-ray absorptiometry using an Alpha DPX-type (GE Lunar Corp., Madison, WI). Bone mass was assessed by means of BMD $\left(\mathrm{g} / \mathrm{cm}^{2}\right)$, using the T-score and Z-score. Osteoporosis was defined on the basis of dual energy X-ray absorptiometry, according to the World Health Organization, when the T-score was at least 2.5 standard deviations (SD) below the average young adult value, a value of $\pm 1 \mathrm{SD}$ was defined as normal, and between -1.0 and -2.5 SD was defined as osteopenia. ${ }^{9}$

Vertebral fractures $\left(\mathrm{T}_{4}-\mathrm{L}_{5}\right)$ were diagnosed with $\mathrm{X}$-rays of the dorsolumbar spine, and fracture evaluations were made by an experienced radiologist using Genant's semi-quantitative method. ${ }^{10}$

Fractures other than spinal fractures such as femur, humerus, or forearm fractures were diagnosed through questioning the subjects. Fractures which occurred as a result of minor trauma such as falling from standing height were considered to be osteoporotic fractures.

\section{Statistical analysis}

Bivariate analysis was used to compare demographic variables as well as variables related to RA in patients with and without treatment with corticosteroids. Student's t-test was used for comparing variables with continuous normal distribution, the Mann-Whitney $\mathrm{U}$ test was used for comparing variables with continuous nonnormal distribution, and the Chi-square test was used for dichotomous variables. We performed a multivariate analysis for the variables which are significantly associated with OP. We used other models of logistic regression where OP represented the dependent variable, and the independent variables were those which were statistically associated with $\mathrm{OP}$ in the bivariate analysis. The variables were included in the regression equation through the stepwise method. $P$ was considered statistically significant at a value of less than 0.05 . Statistical analysis was performed using a computer program (MedCalc for Windows, v10, Mariakerke, Belgium).

\section{RESULTS}

Demographic characteristics of the group are given in Table 1. The mean age of the patients was 62.77 years, and the distribution by age showed that only $2.3 \%$ were under the age of $50,36.9 \%$ were aged between 50 and 59 years, $46.9 \%$ were aged between 60-70 years, and $13.8 \%$ were aged over 70 years. The majority of 
the participants $(78.46 \%)$ came from urban areas, the medium BMI was $27.74 \mathrm{~kg} / \mathrm{m}^{2}$, the median age of menopause was 46.35 years, the median duration of menopause was 16.42 years, and the median age of menarche was 14.02 years. The majority of the patients were non-smokers (82.3\%).

A measurement of $\mathrm{BMD}$ revealed that $44.62 \%$ of the patients had OP, 30.0\% had osteopenia, and only $25.39 \%$ had BMD within the normal range (Table 1). Approximately $37.69 \%$ of the patients had spinal, and $35.38 \%$ had femoral OP.
The mean value of $\mathrm{BMD}$ was $0.94 \mathrm{~g} / \mathrm{cm}^{2}$ at the level of the lumbar spine $\left(\mathrm{L}_{2}-\mathrm{L}_{4}\right), 0.81 \mathrm{~g} / \mathrm{cm}^{2}$ at the right femoral neck, $0.80 \mathrm{~g} / \mathrm{cm}^{2}$ at the left femoral, $0.83 \mathrm{~g} / \mathrm{cm}^{2}$ at the total right hip, and $0.81 \mathrm{~g} / \mathrm{cm}^{2}$ at the total left hip.

The dependent variables of RA are presented in Table 1. None of the patients had RA in stage I. The mean mHAQ score was $1.61 \pm 0.50$, the mean value of DAS28 was 4.77 , the mean ESR was $48.62 \mathrm{~mm} / \mathrm{h}$, and the mean CRP was $8.62 \mathrm{mg} / \mathrm{dl}$.

The majority of the patients were in stage II (48.5\%), 30.8\% were in stage III, and 20.8\% were in stage IV RA.

Table 1. General features of study group $(n=130)$

\begin{tabular}{|c|c|c|c|}
\hline Demographic features & $\mathrm{n}$ & $\%$ & Mean \pm SD \\
\hline Age (years) & & & $62.77 \pm 7.51$ \\
\hline \multicolumn{4}{|l|}{ Environment } \\
\hline Urban & 102 & 78.46 & \\
\hline Rural & 28 & 21.54 & \\
\hline Weight (kg) & & & $67.43 \pm 11.33$ \\
\hline Height $(\mathrm{cm})$ & & & $1.56 \pm 0.06$ \\
\hline Body mass index $\left(\mathrm{kg} / \mathrm{m}^{2}\right)$ & & & $27.74 \pm 4.37$ \\
\hline Menarche (years) & & & $14.02 \pm 2.02$ \\
\hline Menopause (years) & & & $46.35 \pm 4.82$ \\
\hline Duration of menopause (years) & & & $16.42 \pm 8.15$ \\
\hline Smoker & 23 & 17.69 & \\
\hline Former smoker & 18 & 13.85 & \\
\hline \multicolumn{4}{|l|}{ Bone mineral density-T-score } \\
\hline Osteoporosis & 58 & 44.62 & \\
\hline Osteoporosis lumbar spine & 49 & 37.69 & \\
\hline Osteoporosis femoral neck & 46 & 35.38 & \\
\hline Osteopenia & 39 & 30.00 & \\
\hline Normal body mass index & 33 & 25.39 & \\
\hline \multicolumn{4}{|l|}{ Bone mineral density $\left(\mathrm{g} / \mathrm{cm}^{2}\right)$} \\
\hline Lumbar spine $\left(\mathrm{L}_{2}-\mathrm{L}_{4}\right)$ & & & $0.94 \pm 0.17$ \\
\hline Right femoral neck & & & $0.81 \pm 0.14$ \\
\hline Left femoral neck & & & $0.80 \pm 0.15$ \\
\hline Total right hip & & & $0.83 \pm 0.18$ \\
\hline Total left hip & & & $0.81 \pm 0.21$ \\
\hline \multicolumn{4}{|l|}{ Rheumatoid arthritis dependent variables } \\
\hline \multicolumn{4}{|l|}{ Rheumatoid arthritis stage } \\
\hline I & 0 & 0 & \\
\hline II & 63 & 48.5 & \\
\hline III & 40 & 30.8 & \\
\hline IV & 27 & 20.8 & \\
\hline Rheumatoid factor & 97 & 74.6 & \\
\hline Extra-articular manifestations & 33 & 25.4 & \\
\hline Age of rheumatoid arthritis onset (years) & & & $54.86 \pm 9.79$ \\
\hline Rheumatoid arthritis duration (years) & & & $7.91 \pm 7.85$ \\
\hline Modified health assessment questionnaire & & & $1.61 \pm 0.50$ \\
\hline Disease activity score 28 & & & $4.77 \pm 1.2$ \\
\hline Erythrocyte sedimentation rate $(\mathrm{mm} / \mathrm{h})$ & & & $48.62 \pm 29.45$ \\
\hline C-reactive protein $(\mathrm{mg} / \mathrm{dL})$ & & & $8.62 \pm 18.49$ \\
\hline \multicolumn{4}{|l|}{ Extra-articular manifestations } \\
\hline Simple chronic anemia & 27 & 19.23 & \\
\hline Rheumatoid nodules & 10 & 7.69 & \\
\hline Pulmonary fibrosis & 3 & 2.3 & \\
\hline
\end{tabular}


Extra-articular manifestations were present in $25.4 \%$ of the patients, among which 27 patients (19.23\%) presented chronic anemia, 10 patients (7.69\%) presented rheumatoid nodules, and three patients $(2.3 \%)$ had pulmonary fibrosis (Table 1 ).

Rheumatoid arthritis was seropositive in $74.6 \%$ of the patients. An assessment of DAS28 showed that $11.5 \%(n=15)$ of the patients had reduced disease severity (DAS28 $\leq 3.2), 43.8 \%(n=57)$ had moderate activity (DAS28 between 3.2 and 5.1), and $44.6 \%(n=58)$ had significantly high activity (DAS28 >5.1). C-reactive protein level was higher than $20 \mathrm{mg} / \mathrm{dl}$ in 16 patients (12.31\%), and ESR was higher than $20 \mathrm{~mm} / \mathrm{h}$ in 97 patients (74.62\%).

Fifty-eight percent of the patients used 7.5-10 mg/day prednisone equivalent of corticosteroids. Patients on corticosteroid treatment received corticosteroids for more than one year. Regarding other treatments, the majority of the patients received leflunomide (49\%), followed by those who received methotrexate (44\%), combinations of disease modifying antirheumatic drugs (21\%), and hydroxychloroquine (16\%), sulfasalazine (14\%), and biological therapy (9\%). No patient received anti-osteoporotic medication.

Table 2 shows the bivariate analysis of the demographic and RA related variables in patients with and without OP. Osteoporosis was significantly associated with old age, urban environment, lower body weight, lower BMI, late menarche, longer duration of menopause, stage IV RA, the presence of extra-articular manifestations and RF, higher duration of RA, higher ESR, higher CRP, higher mHAQ score, and higher DAS28. Therefore, rural environment

Table 2. Comparison between patients with and without osteoporosis

\begin{tabular}{|c|c|c|c|c|c|c|c|}
\hline & \multicolumn{3}{|c|}{$\begin{array}{c}\text { T-score }(>-2.5) \\
(n=72)\end{array}$} & \multicolumn{3}{|c|}{$\begin{array}{c}\text { T-score }(<-2.5) \\
(n=58)\end{array}$} & \multirow[b]{2}{*}{$p$} \\
\hline & $\mathrm{n}$ & $\%$ & Mean \pm SD & $\mathrm{n}$ & $\%$ & Mean \pm SD & \\
\hline \multicolumn{8}{|l|}{ Demographic variables } \\
\hline Age (years) & & & $58.75 \pm 5.37$ & & & $67.76 \pm 6.79$ & $<0.0001$ \\
\hline Weight (kg) & & & $70.58 \pm 11.87$ & & & $63.52 \pm 9.34$ & 0.0003 \\
\hline Height $(\mathrm{cm})$ & & & $1.56 \pm 0.07$ & & & $1.56 \pm 0.07$ & 0.673 \\
\hline Body mass index $\left(\mathrm{kg} / \mathrm{m}^{2}\right)$ & & & $28.97 \pm 4.66$ & & & $26.22 \pm 3.47$ & 0.0003 \\
\hline Menarche (years) & & & $13.54 \pm 1.45$ & & & $14.60 \pm 2.44$ & 0.002 \\
\hline Menopause (years) & & & $46.58 \pm 4.46$ & & & $46.05 \pm 5.28$ & 0.534 \\
\hline Duration of menopause (years) & & & $12.17 \pm 6.87$ & & & $21.71 \pm 6.35$ & $<0.0001$ \\
\hline Smoker & 9 & 12.50 & & 14 & 24.14 & & 0.134 \\
\hline Former-smoker & 12 & 16.67 & & 6 & 10.34 & & 0.434 \\
\hline \multicolumn{8}{|l|}{ Rheumatoid arthritis } \\
\hline \multicolumn{8}{|l|}{ Rheumatoid arthritis stage } \\
\hline II & 48 & 66.67 & & 15 & 25.86 & & $<0.0001$ \\
\hline III & 18 & 25.00 & & 22 & 37.93 & & 0.162 \\
\hline IV & 6 & 8.33 & & 21 & 36.21 & & 0.0002 \\
\hline Rheumatoid factor, & 42 & 58.33 & & 55 & 95.83 & & $<0.0001$ \\
\hline Extra-articular manifestations & 6 & 8.33 & & 27 & 46.55 & & $<0.0001$ \\
\hline Age at rheumatoid arthritis onset (years) & & & $54.17 \pm 5.64$ & & & $55.72 \pm 13.25$ & 0.369 \\
\hline Duration of rheumatoid arthritis (years) & & & $4.58 \pm 3.16$ & & & $12.03 \pm 9.78$ & $<0.0001$ \\
\hline Modified Health Assessment Questionnaire & & & $1.52 \pm 0.52$ & & & $1.73 \pm 0.45$ & 0.021 \\
\hline Disease Activity Score & & & $4.39 \pm 1.23$ & & & $5.24 \pm 0.98$ & $<0.0001$ \\
\hline Erythrocyte sedimentation rate $(\mathrm{mm} / \mathrm{h})$ & & & $35.21 \pm 20.13$ & & & $65.26 \pm 30.80$ & $<0.0001$ \\
\hline C-reactive protein $(\mathrm{mg} / \mathrm{dL})$ & & & $3.14 \pm 4.44$ & & & $15.41 \pm 25.78$ & $<0.0001$ \\
\hline \multicolumn{8}{|l|}{ Rheumatoid arthritis treatment } \\
\hline Corticosteroids & 36 & 50.00 & & 40 & 68.97 & & 0.045 \\
\hline \multicolumn{8}{|l|}{ Medications } \\
\hline Methotrexate & 21 & 29.17 & & 37 & 63.79 & & 0.0002 \\
\hline Sulfasalazine & 9 & 12.5 & & 9 & 15.52 & & 0.810 \\
\hline Leflunomide & 36 & 50.00 & & 27 & 46.55 & & 0.830 \\
\hline Hydroxychloroquine & 15 & 20.83 & & 6 & 10.34 & & 0.169 \\
\hline DMARDs combinations & 9 & 12.50 & & 18 & 31.03 & & 0.017 \\
\hline Biological therapy & 9 & 12.50 & & 3 & 5.17 & & 0.258 \\
\hline
\end{tabular}


Table 3. Logistic regression usage for evaluating the implication of demographic variables (independent variables) in the occurrence of osteoporosis (dependent variables)

\begin{tabular}{lccccc}
\hline Variable & Coefficient & SD & $p$ & Odds ratio & 95\% CI \\
\hline Age & 0.51 & 0.14 & 0.0004 & 1.67 & 1.26 to 2.22 \\
Body mass index & -0.73 & 0.20 & 0.0003 & 0.47 & 0.32 to 0.71 \\
Duration of menopause & 0.19 & 0.08 & 0.0228 & 1.20 & 1.02 to 1.41 \\
\hline SD: Standard deviation; CI: Confidence interval. \\
Logistic regression shows that age, BMI and duration of menopause may be independent risk factors for osteoporosis.
\end{tabular}

Table 4. Logistic regression usage for identifying rheumatoid arthritis variables (independent variables) which may be risk factors for osteoporosis

\begin{tabular}{lccccc}
\hline Variable & Coefficient & SD & $p$ & Odds ratio & $95 \%$ CI \\
\hline Rheumatoid factor & 2.25 & 0.85 & 0.0052 & 9.5 & 1.96 to 46.12 \\
Extra-articular manifestations & 2.51 & 0.90 & 0.0051 & 12.32 & 2.12 to 71.52 \\
Rheumatoid arthritis duration & 0.31 & 0.09 & 0.0003 & 1.36 & 1.16 to 1.61 \\
mHAQ & 2.94 & 0.98 & 0.0027 & 0.05 & 0.01 to 0.36 \\
DAS28 & 0.61 & 0.31 & 0.0492 & 1.83 & 1.00 to 3.35 \\
C-reactive protein & 0.15 & 0.05 & 0.0026 & 1.15 & 1.05 to 1.27 \\
SD: Standard deviation; CI: Confidence interval; mHAQ: Modified health assessment questionnaire; DAS28: Disease Activity Score 28. \\
Logistic regression shows that rheumatoid factor, extra-articular manifestations, rheumatoid arthritis duration, mHAQ score, DAS28, \\
erythrocyte sedimentation rate and C-reactive protein may be risk factors for osteoporosis.
\end{tabular}

and stage II RA seemed to be protective factors for OP. From the background drugs, only methotrexate and DMARs combinations were significantly associated with OP. The use of corticosteroids was statistically significantly associated with osteoporosis.

Logistic regression was used to measure the independent contribution of each factor to OP, including any factor that has been identified in the bivariate analysis and was statistically associated with OP. We explored several logistic regression models as presented in Tables 3 and 4 . We showed that the mHAQ score and DAS28 do not independently contribute to the occurrence of OP (Table 5).

\section{DISCUSSION}

Similarly to our study, an increased frequency of OP (44\%) was also observed in the study of Nolla et al. ${ }^{11}$ Other studies showed a prevalence of OP between $7 \%$ to $26 \%$ at the femoral level, and $19 \%$ to $32 \%$ at the spinal level. ${ }^{12,13}$

Old age and lower BMI seem to be among the independent risk factors for OP. Late menarche and longer duration of menopause are significantly associated with $\mathrm{OP}$, a finding which is in accordance with other studies. Thus we showed that years since menopause may be more important than chronological age in postmenopausal OP. ${ }^{14}$

We further demonstrated that the environment may represent an independent risk factor for OP. Even after adjusting for disability (mHAQ), the risk of OP in people from urban areas is 3.5 times higher compared with rural areas. ${ }^{15} \mathrm{~A}$ reason for this may be that unlike patients in urban areas, patients in rural areas take more physical exercise. It is known that physical exercise represents a stimulus of the musculoskeletal system, and an

Table 5. Logistic regression usage for evaluating mHAQ score and DAS28 contribution (independent variables) to the occurrence of osteoporosis (dependent variables)

\begin{tabular}{lccccc}
\hline Variable & Coefficient & SD & $p$ & Odds ratio & 95\% CI \\
\hline mHAQ & 0.37 & 0.42 & 0.3837 & 1.44 & 0.63 to 3.29 \\
DAS28 & 0.60 & 0.18 & 0.0009 & 1.82 & 1.28 to 2.61 \\
\hline CI: Confidence interval; mHAQ: Modified Health Assessment Questionnaire; DAS28: Disease Activity Score 28. \\
Logistic regression shows that mHAQ score and DAS28 do not contribute independently to the occurrence of osteoporosis.
\end{tabular}


important factor in achieving and maintaining the body's bone capital.

Extra-articular manifestations are statistically associated with OP, but also with higher values of mHAQ, DAS28, ESR, and CRP.

Independent variables were required to achieve some criteria to be included in the stepwise regression. The most important criterion was for an independent variable to be statistically associated with $\mathrm{OP}$ in the bivariate analysis. Another criterion represented the possibility of independent variables to be confounders.

Extra-articular manifestations were statistically associated with OP and higher values of mHAQ, DAS28, ESR, and CRP. Therefore, the presence of RF was statistically associated with OP, but also with higher duration of PR, and higher values of mHAQ, ESR and CRP. To the best of our knowledge, other studies are in contradiction concerning indicating $\mathrm{RF}$ as a risk factor for OP. ${ }^{12,13}$ Moreover, only few studies have evaluated the relationship between extra-articular manifestations and OP. These variables were included in the regression logistic model, which showed that the duration of RA, mHAQ score, DAS28, ESR and CRP may be independent risk factors for OP.

In the bivariate analysis, mHAQ score and DAS28 were statistically associated with OP, and DAS28 and mHAQ score were not independent risk factors for $\mathrm{OP}$ as far as the relationship between mHAQ score and OP could be covered by DAS28.

The study has several limitations. First, it is a non-randomized study, and there are confounding factors. Confounding is a form of bias that can distort the measure of association between an exposure and disease, and must be eliminated. Logistic regression may be an efficient way to control the presence of any potential confounders at once, but the interpretation of the results may be limited due to the possible presence of other variables which may have been omitted. For example, age and the duration of menopause may be confounders, hence older age as well as longer duration of menopause were associated with OP. Furthermore, older women had longer durations of menopause. In the present study, age and the duration of menopause were identified as independent risk factors for OP by using logistic regression. It is difficult to know whether the RA dependent variables, identified as risk factors for $\mathrm{OP}$ in the logistic regression, can be confounders (e.g. ESR and CPR can be confounders for DAS28).

\section{Conclusion}

Although OP may be common in patients with RA, it is difficult to estimate which particular targets and therapeutics may be the best approach in the future. The demographic variables measured in our study were shown to be involved in the occurrence of OP. Furthermore, the severity of RA was demonstrated to be a possible contributor in the occurrence of $\mathrm{OP}$, without being an independent factor of physical disability. Therefore, we may conclude that OP may occur more frequently in patients with more severe forms of RA, and the duration of the disease tends to be longer in such cases.

\section{Declaration of conflicting interests}

The authors declared no conflicts of interest with respect to the authorship and/or publication of this article.

\section{Funding}

The authors received no financial support for the research and/or authorship of this article.

\section{REFERENCES}

1. Deodhar AA, Woolf AD. Bone mass measurement and bone metabolism in rheumatoid arthritis: a review. $\mathrm{Br} \mathrm{J}$ Rheumatol 1996;35:309-22.

2. Haugeberg G, Uhlig T, Falch JA, Halse JI, Kvien TK. Bone mineral density and frequency of osteoporosis in female patients with rheumatoid arthritis: results from 394 patients in the Oslo County Rheumatoid Arthritis register. Arthritis Rheum 2000;43:522-30.

3. McGrath $\mathrm{C}$, Bedi R. An evaluation of a new measure of oral health related quality of life--OHQoL-UK(W). Community Dent Health 2001;18:138-43.

4. Arnett FC, Edworthy SM, Bloch DA, McShane DJ, Fries JF, Cooper NS, et al. The American Rheumatism Association 1987 revised criteria for the classification of rheumatoid arthritis. Arthritis Rheum 1988;31:315-24.

5. van der Heijde DM, van 't Hof $\mathrm{M}$, van Riel PL, van de Putte LB. Development of a disease activity score based on judgment in clinical practice by rheumatologists. J Rheumatol 1993;20:579-81. 
6. ICSH recommendations for measurement of erythrocyte sedimentation rate. International Council for Standardization in Haematology (Expert Panel on Blood Rheology) J Clin Pathol 1993;46:198-203.

7. Pincus T, Summey JA, Soraci SA Jr, Wallston KA, Hummon NP. Assessment of patient satisfaction in activities of daily living using a modified Stanford Health Assessment Questionnaire. Arthritis Rheum 1983;26:1346-53.

8. Kindmark $\mathrm{CO}$. The concentration of $\mathrm{C}$-reactive protein in sera from healthy individuals. Scand J Clin Lab Invest 1972;29:407-11.

9. Kanis JA, Melton LJ 3rd, Christiansen C, Johnston CC, Khaltaev N. The diagnosis of osteoporosis. J Bone Miner Res 1994;9:1137-41.

10. Genant HK, Wu CY, van Kuijk C, Nevitt MC. Vertebral fracture assessment using a semiquantitative technique. J Bone Miner Res 1993;8:1137-48.

11. Nolla JM, Fiter J, Gómez-Vaquero C, Alegre JJ, Valverde J, Roig-Escofet D. Value of clinical factors in selecting postmenopausal women with rheumatoid arthritis for bone densitometry. Ann Rheum Dis
2001;60:799-801.

12. Sinigaglia L, Nervetti A, Mela Q, Bianchi G, Del Puente A, Di Munno O, et al. A multicenter cross sectional study on bone mineral density in rheumatoid arthritis. Italian Study Group on Bone Mass in Rheumatoid Arthritis. J Rheumatol 2000;27:2582-9.

13. Forsblad D'Elia H, Larsen A, Waltbrand E, Kvist G, Mellström D, Saxne T, et al. Radiographic joint destruction in postmenopausal rheumatoid arthritis is strongly associated with generalised osteoporosis. Ann Rheum Dis 2003;62:617-23.

14. Lodder MC, de Jong Z, Kostense PJ, Molenaar ET, Staal K, Voskuyl AE, et al. Bone mineral density in patients with rheumatoid arthritis: relation between disease severity and low bone mineral density. Ann Rheum Dis 2004;63:1576-80.

15. Haugeberg G, Uhlig T, Falch JA, Halse JI, Kvien TK. Bone mineral density and frequency of osteoporosis in female patients with rheumatoid arthritis: results from 394 patients in the Oslo County Rheumatoid Arthritis register. Arthritis Rheum 2000;43:522-30. 